\title{
DUPLA JORNADA DE TRABALHO NA ENFERMAGEM: PARADIGMA DA PROSPERIDADE OU REFLEXO DO MODELO NEOLIBERAL?
}

\section{DOUBLE WORKING HOURS IN NURSING: PARADIGM OF PROSPERITY OR REFLECTION OF THE NEOLIBERAL MODEL?}

\section{DOBLE JORNADA LABORAL EN ENFERMERIA: ¿PARADIGMA DE PROSPERIDAD O REFLEXIÓN DEL MODELO NEOLIBERAL?}

\author{
Samira Silva Santos Soares ${ }^{1}$ \\ Márcia Tereza Luz Lisboa ${ }^{2}$ \\ Ana Beatriz Azevedo Queiroz ${ }^{3}$ \\ Karla Gualberto Silva ${ }^{4}$ \\ Jandra Cibele Rodrigues de Abrantes Pereira Leite \\ Norma Valéria Dantas de Oliveira Souza ${ }^{6}$
}

Como citar este artigo: Soares SSS, Lisboa MTL, Queiroz ABA, Silva KG, Leite JCRAP, Souza NVDO. Dupla jornada de trabalho na enfermagem: paradigma da prosperidade ou reflexo do modelo neoliberal? Rev baiana enferm. 2021;35:e38745.

Objetivo: compreender os motivos que sustentam a prática da dupla jornada de trabalho na enfermagem. Método: pesquisa qualitativa, realizada com 30 trabalhadores de enfermagem com dupla jornada de trabalho praticada em instituições do setor público e/ou privado, em atividades assistenciais e/ou gerenciais de enfermagem, captados pela técnica snowball, entre janeiro e março de 2019, em Eunápolis, Bahia, Brasil. Os dados foram coletados mediante aplicação de questionário e entrevista semiestruturada, processados pelo Iramuteq ${ }^{\circledR}$ e submetidos à análise lexical via Classificação Hierárquica Descendente. Resultados: emergiram duas classes: A precarização do trabalho de enfermagem; e Aspirações e necessidades dos trabalhadores de enfermagem. Considerações Finais: a prática da dupla jornada de trabalho na enfermagem está relacionada à forte influência do modelo neoliberal sobre o processo de trabalho da enfermagem, que não oferece ao trabalhador a retribuição material adequada em função das atividades desempenhadas e também se relaciona à questão cultural decorrente da facilidade de conciliar múltiplos empregos.

Descritores: Enfermagem. Jornada de Trabalho. Saúde do Trabalhador. Legislação de Enfermagem. Condições de Trabalho.

\footnotetext{
Enfermeira. Mestre em Enfermagem. Universidade do Estado do Rio de Janeiro. Professora Substituta da Universidade Federal do Rio de Janeiro. Rio de Janeiro, RJ, Brasil.samira_opg@hotmail.com. http://orcid.org/0000-0001-9133-7044.

Enfermeira. Doutora em Enfermagem. Professora Titular da Universidade Federal do Rio de Janeiro. Rio de Janeiro, RJ, Brasil. http://orcid.org/0000-000 I-68 I3-7474 Enfermeira. Doutora em Enfermagem. Professora Associada da Universidade Federal do Rio de Janeiro. Rio de Janeiro, RJ, Brasil. http://orcid.org/0000-00032447-6137.

Enfermeira. Mestre em Enfermagem. Rio de Janeiro, RJ, Brasil. http://orcid.org/0000-0002-7870-0600.

Enfermeira. Mestre em Enfermagem. Universidade Federal do Rio de Janeiro. Rio de Janeiro, RJ, Brasil. http://orcid.org/0000-0002-8676-3898.

Enfermeira. Doutora em Enfermagem. Professora Titular da Universidade do Estado do Rio de Janeiro. Rio de Janeiro, RJ, Brasil. http://orcid.org/0000-0002-29363468.
} 
Objective: to understand the reasons that support the practice of double working hours in nursing. Method: qualitative research, conducted with 30 mursing workers with double working hours practiced in public and/or private sector institutions, in nursing care and/or management activities, recruited by the snowball technique, between January and March 2019, in Eunápolis, Babia, Brazil. Data were collected by applying a questionnaire and semi-structured interview, processed by Iramuteq ${ }^{\circledR}$ and submitted to lexical analysis through Descending Hierarchical Classification. Results: two classes emerged: The precariousness of nursing work; and Aspirations and needs of nursing workers. Final Thoughts: the practice of double working hours in nursing is related to the strong influence of the neoliberal model on the nursing work process, which does not offer the worker adequate material remuneration according to the activities performed and is also related to the cultural issue resulting from the ease of reconciling multiple jobs.

Descriptors: Nursing. Work Hours. Occupational Health. Legislation, Nursing. Working Conditions.

Objetivo: entender las razones que apoyan la práctica de doble jornada laboral en enfermería. Método: investigación cualitativa, realizada con 30 trabajadores de enfermería con doble jornada de trabajo practicada en instituciones del sector público y/o privado, en cuidados de enfermería y/o actividades de gestión, captadas por la técnica de bola de nieve, entre enero y marzo de 2019, en Eunápolis, Babia, Brasil. Los datos se recopilaron aplicando un cuestionario y una entrevista semiestructurada, procesada por Iramuteq ${ }^{\circledR}$ y sometidas a análisis léxicos a través de la Clasificación Jerárquica Descendente. Resultados: surgieron dos clases: La precariedad del trabajo de enfermeria; $y$ aspiraciones y necesidades de los trabajadores de enfermería. Consideraciones finales: la práctica de la doble jornada de trabajo en enfermería está relacionada con la fuerte influencia del modelo neoliberal en el proceso de trabajo de enfermería, que no ofrece al trabajador una remuneración material adecuada de acuerdo con las actividades realizadas y también está relacionada con la cuestión cultural resultante de la facilidad de conciliación de múltiples puestos de trabajo.

Descriptores: Enfermería. Horas de Trabajo. Salud Laboral. Legislación de Enfermería. Condiciones de Trabajo.

\section{Introdução}

A dupla jornada de trabalho é prática comum entre os trabalhadores de enfermagem que assumem mais de um vínculo trabalhista e, consequentemente, deparam-se com cargas horárias exaustivas, em decorrência das horas efetivamente trabalhadas. Estudos anteriores ${ }^{(1-3)}$ mencionam que os trabalhadores de enfermagem são impulsionados a assumir múltiplas jornadas laborais, a fim de garantir o sustento econômico. Entretanto, desde que momento a remuneração dos trabalhadores de enfermagem deixou de ser suficiente? Estariam, porventura, os trabalhadores de enfermagem influenciados por um paradigma de prosperidade, que aposta na dupla jornada de trabalho como a possibilidade de aquisição de bens e acúmulo de riqueza? Além disso, será que, para além da questão financeira, existem outros motivos que sustentam a prática da dupla jornada de trabalho na enfermagem contemporânea?

Ao refletir sobre esses questionamentos, pode-se considerar que a problemática da dupla jornada de trabalho entre os trabalhadores de enfermagem tem multifatores. Apesar de a Lei $n^{\circ} 7.498 / 86$ regulamentar o exercício profissional da enfermagem brasileira, não há um dispositivo legal que especifique sobre a jornada de trabalho desses profissionais. Assim, quando esses trabalhadores, inseridos em um mercado de economia capitalista, deparam-se com oportunidades de emprego que lhes permitem, devido à flexibilidade das escalas de trabalho, conciliar dois ou mais vínculos de trabalho, não hesitam em aceitar.

$\mathrm{Na}$ tentativa de conciliar as jornadas de trabalho, recorre-se frequentemente a turnos diurnos e noturno, que exigem adaptação que gera desgaste, trazendo consequências para a saúde do trabalhador, ao comprometer a capacidade produtiva e provocar perturbações nas funções orgânicas e físicas. Ademais, registram-se prejuízos para as instituições e segurança do paciente, devido ao déficit na capacidade de concentração e atenção, bem como comprometimento nas relações da vida social ${ }^{(4)}$.

Ao investigar o estado da arte, fez-se um levantamento da produção científica brasileira 
sobre essa temática, considerando como recorte temporal o período de 2000 a 2018. Este teve em vista o marco histórico representado pelo projeto de Lei $n^{\circ} 2.295 / 2000$, que dispõe sobre a regulamentação da jornada de 30 horas semanais para a enfermagem. Percebe-se que, no Brasil, são poucos os estudos que tratam especificamente sobre a dupla jornada de trabalho entre os trabalhadores de enfermagem ${ }^{(5-7)}$.

Todavia, com base nesses estudos, é possível afirmar que essa prática não está restrita a um único município, estado ou região do país. Há indícios da ocorrência em diferentes cenários e contextos de atuação da enfermagem contemporânea. Esses aspectos confirmam a necessidade da produção de conhecimento que supere as lacunas existentes sobre a temática, assim como possibilite o debruçar sobre a problemática com maior imersão.

Cabe considerar que não foi possível identificar o exato momento em que a prática da dupla jornada de trabalho teve início, nem os motivos que concorreram para a perpetuação. Entretanto, acredita-se que a implantação do modelo neoliberal, bem como a crise econômica que marcou as últimas três décadas do século XX, acentuando-se, a partir do ano de 2008, agravou essa situação em virtude dos patamares salariais cada vez mais baixos ${ }^{(8)}$. Deste modo, no intuito de melhor compreender a problemática em tela, utilizaram-se pesquisas relacionadas ao modelo neoliberal e à precarização do trabalho de enfermagem.

Assim, este estudo justifica-se e torna-se relevante, por trazer reflexões que sirvam de alerta, principalmente aos trabalhadores de enfermagem, pois, vivendo do trabalho e pelo trabalho, é possível que se deparem com um jogo de forças contraditórias que extrapolem o alcance de objetivos pessoais, conduzindo-os a um processo de autoaceleração, alienação e distanciamento de práticas emancipatórias, que os tornem vulneráveis ao processo de adoecimento, além de comprometer a qualidade da assistência de enfermagem prestada.
Desse modo, objetivou-se compreender os motivos que sustentam a prática da dupla jornada de trabalho na enfermagem.

\section{Método}

Trata-se de pesquisa qualitativa que procurou atender aos passos recomendados pelos Critérios Consolidados para Relatar uma Pesquisa Qualitativa (COREQ). Este é um guia de pesquisa composto por 32 itens considerados necessários ao desenvolvimento de estudos qualitativos ${ }^{(9)}$.

O estudo foi realizado na cidade de Eunápolis, sede do município de mesmo nome, situada no nordeste brasileiro, no estado da Bahia, Brasil, à distância de $396 \mathrm{~km}$ da capital (Salvador). Em termos populacionais, tem 112.318 habitantes ${ }^{(10)}$ e conta com cerca de 447 profissionais de enfermagem que atuam nos diversos serviços de saúde do município ${ }^{(11)}$. Entretanto, não é possível conhecer o número exato desses trabalhadores que atuam com dupla jornada de trabalho.

A cidade de Eunápolis foi escolhida como cenário de estudo por ter sido o local onde a observação empírica ocorreu. Surgiram ali as primeiras inquietações sobre a temática e o interesse pela pesquisa.

O estudo foi realizado com 30 trabalhadores de enfermagem com dupla jornada de trabalho, captados pela técnica snowball (bola de neve), durante os meses de janeiro e março de 2019.

Estabeleceu-se como critérios de inclusão para participar do estudo: trabalhadores de enfermagem (enfermeiros e técnicos de enfermagem) com dupla jornada de trabalho, em decorrência de ter mais de um vínculo trabalhista na área da enfermagem, praticados em instituições do setor público e/ou privado, em atividades assistenciais e/ou gerenciais de enfermagem; residir no município de Eunápolis ou em municípios que integram a mesma região de saúde, o que inclui as cidades de Belmonte, Guaratinga, Itabela, Itagimirim, Itapebi, Porto Seguro e Santa Cruz Cabrália.

Caracterizou-se como critério de exclusão: trabalhadores de enfermagem (enfermeiros e 
4

Dupla jornada de trabalho na enfermagem: paradigma da prosperidade ou reflexo do modelo neoliberal?

técnicos de enfermagem) com dupla jornada de trabalho há menos de um ano consecutivo. Tal critério fundamentou-se na crença de que o período de um ano é minimamente necessário para que tais profissionais familiarizem-se com as rotinas necessárias ao cumprimento dessas duas jornadas, em instituições diferentes, considerem as vantagens e as desvantagens dessa prática, avaliem o retorno financeiro e os impactos produzidos por ela no trabalho e na vida pessoal.

A coleta de dados foi realizada por meio de questionário, para caracterização dos participantes, e entrevista semiestruturada, a qual constou de questões norteadoras relacionadas à vivência dos entrevistados quanto à dupla jornada de trabalho. As entrevistas foram realizadas conforme disponibilidade do trabalhador e fora dos locais de trabalho, após a assinatura do Termo de Consentimento Livre e Esclarecido (TCLE). A gravação das entrevistas foi realizada com a concordância dos respondentes, com duração entre 25 minutos e 1 hora e 30 minutos. Após transcritas, os textos provenientes foram revisados em relação à ortografia, sem que a essência fosse alterada, e devolvidos aos participantes para leitura e aprovação do conteúdo.

Destaca-se que houve dez recusas à participação na pesquisa e o motivo alegado foi a indisponibilidade de tempo, devido à extensa jornada de trabalho. A coleta de dados foi interrompida a partir do momento em que se considerou atingir a saturação teórica e empírica e, portanto, os dados produzidos mostravam-se satisfatórios, pois já respondiam às questões norteadoras e aos objetivos propostos. Depois da sexta entrevista com enfermeiros e da décima quarta entrevista com técnicos de enfermagem, observou-se a repetição dos dados e não surgimento de nova informação. Portanto, a coleta de novos dados acrescentaria poucas informações à discussão.

Para análise de conteúdo, aplicou-se a análise lexical dos dados, por meio do software Interface de $\mathrm{R}$ pour les Analyses Multidimensionnelles de Textes et de Questionnaires (IRAMUTEQ ${ }^{\circledR}$ ), versão 0.7 alpha 2. Para realização da análise, seguiram-se os seguintes passos: organização e preparação dos dados, com a transcrição das entrevistas na íntegra, codificação e disposição dos dados em formato de corpus textual. Como corpus, entende-se todo o material oriundo das entrevistas previamente organizado em um único arquivo de texto pelo pesquisador; leitura dos dados para obter a percepção geral das ideias expressas pelos entrevistados; e processamento dos dados por meio do Método de Reinert. Nesta última etapa, utilizou-se o software IRAMUTEQ ${ }^{\circledR}$ que, ao processar o corpus textual gerou, por meio da Classificação Hierárquica Descendente (CHD), a divisão do corpus em classes, com base na similaridade e na diferença entre as sentenças. A CHD possibilitou identificar os léxicos prevalentes em cada contexto e os Segmentos de Texto (ST) de cada classe. Os ST constituem as principais unidades de análise textual deste tipo de software ${ }^{(12)}$.

Após as etapas citadas, foi possível, com base nos dados brutos apresentados pelo software, o tratamento dos resultados - inferência e interpretação, etapa na qual as pesquisadoras procuraram tornar os resultados significativos e válidos. Nesta fase, ocorreu a dedução de maneira lógica, a descrição e análise das diferentes classes encontradas pelo software. Nesse momento, com o detalhamento das entrevistas, retornou-se ao referencial teórico e valeu-se de outros achados encontrados na literatura, buscando embasar a análise, dando sentido à interpretação e buscando o que estava subentendido no significado das palavras, para um enunciado mais aprofundado dos discursos.

Os dados foram analisados com base nos elementos textuais, ressaltando considerações críticas sobre o modelo neoliberal e a precarização do trabalho de enfermagem. Salienta-se que as classes apresentadas responderam ao objetivo deste estudo.

$\mathrm{Na}$ apresentação dos resultados, objetivando manter o anonimato dos participantes, no final dos ST, adotou-se a codificação "E" ou "Tec" que representam, respectivamente, os participantes enfermeiros ou técnicos de enfermagem, seguida de número arábico que indica a sequência cronológica da interlocução realizada. 
O desenvolvimento do estudo respeitou os preceitos éticos de participação voluntária, esclarecida e consentida, conforme as Resoluções $n^{\circ} 466 / 2012$ e no 510/2016, da Comissão Nacional de Ética em Pesquisa, do Conselho Nacional de Saúde, sendo submetido à análise e emissão de parecer favorável do Comitê de Ética em Pesquisa da Escola de Enfermagem Anna Nery. Assim, por meio de adesão voluntária, os participantes recrutados foram resguardados mediante a assinatura do TCLE, respeitando-se autonomia, dignidade e anonimato.

\section{Resultados}

Fizeram parte desta análise 30 trabalhadores de enfermagem, com dupla jornada de trabalho, decorrente de dois vínculos empregatícios. Deste total, 10 eram enfermeiros e 20, técnicos de enfermagem. Dos 10 enfermeiros que compuseram a amostra, 6 iniciaram a carreira na enfermagem como técnicos de enfermagem e, posteriormente, ingressaram no curso de graduação. Destes, 3 estavam inseridos no mercado de trabalho, atuando ora como técnico de enfermagem, ora como enfermeiro. Dos 20 técnicos de enfermagem, 2 conciliavam, além da dupla jornada de trabalho, os estudos, pois optaram por cursar a graduação em enfermagem ofertada em curso de educação a distância, ministrado no período noturno, em instituição de ensino da rede privada.

A renda líquida declarada pelos participantes da pesquisa, ao considerarem o somatório dos salários recebidos em decorrência dos vínculos de trabalho, aponta que os técnicos de enfermagem com dupla jornada de trabalho recebiam entre dois e quatro salários mínimos. Entre os enfermeiros, a faixa salarial predominante esteve entre quatro e dez salários mínimos.

Além do exposto, com base no processamento dos dados no software IRAMUTEQ ${ }^{\circledR}$, foi possível identificar os principais léxicos de cada classe. Assim, ao analisar os segmentos de textos e os contextos em que esses léxicos eram evocados, identificaram-se os temas desenvolvidos em cada classe, o que permitiu denominá-las da seguinte maneira: Precarização do trabalho de enfermagem (classe 1, com 23,31\% do corpus) e Aspirações e necessidades dos trabalhadores de enfermagem (classe 2, com 14,93\% do corpus). Ambas serão abordadas a seguir.

\section{Classe 1: Precarização do trabalho de enfermagem}

Nesta classe, entre os léxicos mais frequentes, encontraram-se: salário, emprego, ganhar, real, valor, renda, 30 horas, piso salarial, questão financeira, cultura.

Nesta perspectiva, os trabalhadores de enfermagem enfatizaram que o principal motivo que os impulsionou a buscar um segundo vínculo trabalhista e, assim, assumir uma dupla jornada de trabalho foi o baixo salário recebido pela categoria, como pode ser verificado nos excertos seguintes:

Primeiro, o salário. O salário do técnico de enfermagem
é baixo, praticamente um salário minimo, então, para
gente pagar as contas, não tem jeito, a gente tem que
fazer esse corre-corre. (Tec7).
O salário da enfermagem é um pouco defasado, então,
é preciso ter dois empregos para ter uma renda melhor.
Tem enfermeiro que estuda, faz faculdade, e está por aí
ganhando $\$ \$ 1.000,00$ (mil reais) bruto. (E1).

Outro motivo indicado pelos participantes do estudo estava relacionado à situação atual do mercado de trabalho da enfermagem, que, além dos problemas de empregabilidade, em virtude dos frágeis vínculos de trabalho, gerava no trabalhador o medo de perder o emprego, conforme expresso nos relatos sequentes:

Depois do curso superior, eu fiquei muito tempo para conseguir trabalbo. Eu percebi que, como técnica de enfermagem, nunca faltava, mas como enfermeira, sim. Como eu tive muita dificuldade em conseguir entrar no mercado de trabalbo como enfermeira, quando eu arrumei trabalho, eu me apeguei. Me apeguei muito a trabalhar mais, porque eu via que estava dificil para outras pessoas e como eu vou dispensar uma coisa se tem tanta gente precisando? (E2).

Tem o fato de ser contratada também. Isso me faz ficar em dois empregos. Eu já até tentei sair, mas vocêfica com medo, porque você fica à mercê. Você tem medo de sair de um emprego e depois perder o outro e ficar sem nada. Você se sente ameaçado o tempo todo. E tem a questão política, muda o governo, manda todo mundo embora, tem tudo isso. (Tec7). 
Os entrevistados atribuíram a dupla jornada de trabalho também à ausência de um piso salarial digno, à desvalorização da categoria e, até mesmo, à escassez de engajamento político da enfermagem em lutar por melhores condições salariais, como pode ser verificado:

Se nós tivéssemos um piso salarial e fôssemos valorizados como profissionais, não estariamos com essa dupla ou tripla jornada de trabalho. (E10).

A gente não tem valor, a gente nunca foi valorizado. Mas a gente é assim, porque se a gente não se valoriza, ninguém vai dar valor para gente, ninguém vai respeitar a enfermagem, ninguém vai brigar pela gente. (E4).

Os entrevistados apontaram ainda que a sociedade julga que os trabalhadores de enfermagem com dupla jornada de trabalho estão em busca de enriquecer e, por isso, assumem essa rotina considerada até uma loucura. O fato é que, com os vínculos precários e inseguros, esta prática é vista pelos trabalhadores como uma forma de vislumbrar alguma segurança e/ou direito no futuro.

\begin{abstract}
As pessoas acham que eu vou enricar por ter dois empregos. Acham que tenho muito dinheiro e essa não é a realidade. Até pela crise financeira que vivemos. Antigamente, com dois empregos, eu vivia bem. Hoje eu vivo apertado. (E9).
\end{abstract}

As pessoas falam: Pra quê isso? Você não precisa disso, de ficar se matando desse jeito. Isso é loucura! Mas, a gente que sabe. Ninguém conhece as minhas necessidades, ninguém sabe o que eu realmente preciso. (Tec10).

As pessoas procuram um outro emprego com carteira assinada, porque se, no futuro, a pessoa precisar de um afastamento, uma licença maternidade, você tem direito e na prefeitura, não. (E3).

Eu sempre tento ter um emprego com carteira as sinada, pela estabilidade, pensando no futuro, na aposentadoria. (Tec6).

Por fim, identificou-se também que, para além de uma questão financeira, alguns trabalhadores de enfermagem submetiam-se às duplas jornadas de trabalho por uma questão cultural, relacionada à prática do multiemprego, comum às profissões da área da saúde, como pode ser verificado:

Eu não precisava estar em dois empregos, mas eu já me acostumei. (Tec14).

Todo mundo já criou a cultura, de que se trabalha na enfermagem, trabalha em dois ou mais lugares. É cultura, muitas vezes, você não precisa, mas você acostuma de tal forma, que eu mesmo, se eu for ficar em um emprego só, eu vou ter que me readaptar a isso. (Tec2).

Quem não tem dois empregos está fora do contexto. Pra gente, já é comum. A gente acaba pensando que quem tem um emprego só, deve ter uma vida muito boa. (Tec11).

A gente vai pela necessidade, para alcançar nossos objetivos. Eu precisava ter dois empregos, mas com o tempo, o que faz você manter, é o bábito, a cultura. (Tec10).

\section{Classe 2: Aspirações e necessidades dos trabalhadores de enfermagem}

Nesta classe, entre os léxicos mais frequentes, encontraram-se: filho, comprar, carro, pai, pagar, mãe, custo, morar, terreno, manter, ajudar, faculdade, casa própria, aluguel, conquistar.

Considerando-se tais léxicos, os trabalhadores de enfermagem valeram-se do múltiplo emprego e submeteram-se às duplas jornadas de trabalho, a fim de trazer provimento ao lar, oferecer melhores condições de vida aos filhos, por meio do acesso a serviços educacionais de qualidade, além de ajudar pais e familiares, conforme expressaram nas falas:

\begin{abstract}
Economicamente falando, a dupla jornada de trabalbo é uma necessidade, porque tem pai e mãe de família cuidando de seus filhos, netos. Muito profissional ajudando financeiramente outras pessoas. (E1).
\end{abstract}

Como que um pai ou mãe de família vai manter uma casa com $R \$ 1.380$ reais? E isso eu falo porque eu trabalbo à noite. Então, esse valor ainda tem os adicionais, mas o salário do servidor é $R \$ 1.040$ reais. (Tec13).

Eu tenho um amigo, que tem três filhos. Ele me disse que só os módulos da escola, agora no início do ano, ele gastou 7 mil reais, para os filhos permanecerem na escola privada, porque o ensino público na região não é satisfatório. (E10).

Eu trabalbo em prol da minha filba, para conseguir dar uma boa escola para minha filha, pagar um balé, um curso de inglês. (Tec16).

Os trabalhadores de enfermagem também mencionaram que a aquisição de bens materiais somente é possível e/ou foram conquistados em virtude da renda proveniente dos múltiplos empregos, o que motivava a prática da dupla jornada de trabalho.

Depois que eu comecei com os dois empregos foi que eu consegui comprar meu terreno, para construir minha casa. Uma colega que trabalhava comigo, também trabalhava em dois empregos. Ela se afastou de um, mas, depois, ela me disse: Amiga, não deu. Tenho que voltar. Comprei minha casa agora, preciso pagar minha casa, 
então, eu vou ter que voltar, não é porque eu quero não, mas eu preciso. (E5).

Pago um terreno que compramos, ajudo meu esposo a pagar o carro, e como a gente mora em casa de aluguel, ainda temos outras contas. Então, meu custo é muito alto e nós somos muito mal remunerados na enfermagem. Eu me vejo obrigada a ter dois empregos, não é porque eu quero. (Tec20).

Outro aspecto salientado pelos entrevistados foi a necessidade do múltiplo emprego, para que pudessem investir financeiramente na aquisição de conhecimento, isto é, na formação profissional.

As colegas que eu observo precisam de um segundo emprego para dar conta de pagar a faculdade, por exemplo. A maioria delas, os pais não têm condição de pagar faculdade para elas. Estão em dois empregos para conseguir conquistar um objetivo pessoal. (Tec16).

Quando eu fui estudar, eu precisava manter os dois empregos para pagar a faculdade. Então, eu acabei estudando e trabalhando em dois empregos. (E1).

\section{Discussão}

Em relação aos dados dos participantes do estudo, três aspectos merecem atenção: o fato de $60 \%$ dos enfermeiros terem iniciado a carreira como técnicos de enfermagem; a ocorrência de $30 \%$ dos enfermeiros estarem inseridos no mercado de trabalho como técnicos de enfermagem; a situação de que 10\% dos técnicos de enfermagem, além de assumirem dupla jornada de trabalho, ainda relataram conciliar trabalho e estudo.

Quanto ao primeiro aspecto, é comum na enfermagem que os enfermeiros tenham tido o primeiro contato com a profissão por meio da realização do curso técnico ou de auxiliar de enfermagem $^{(1)}$, o que leva à suposição de que esta força de trabalho tenha experiência significativa no exercício da enfermagem, pois há vivência prévia nesse contexto laboral, antes mesmo de se graduarem.

Entretanto, inquieta o fato de que esses profissionais atuem em postos de trabalho com escolaridade inferior à que possuem, como é o caso dos enfermeiros que desenvolvem atividades laborais como técnicos de enfermagem. Essa situação vem sendo denominada na literatura de fenômeno de superqualificação e deve ser vista com cautela, pois pode gerar no trabalhador sentimento de menos valia, quando percebe que a experiência pessoal, o investimento com a qualificação e o conhecimento adquirido não são valorizados pela organização de trabalho ${ }^{(13)}$.

Ademais, o ser humano é um todo indivisível. Assim, é uma situação insólita o fato de em um momento, ele pense e aja como técnico de enfermagem e, em outro, como enfermeiro, uma vez que o conhecimento mais amplo e aprofundado foi apreendido e não pode ser deixado de lado. Nesta perspectiva, enfatiza-se que a defasagem entre as aspirações que o sistema de ensino produz e as oportunidades que o mercado oferece é geradora de desencantamento, de profundo mal-estar, resultando na percepção e constatação de que o mundo do trabalho é excludente, podendo, inclusive, culminar na evasão do profissional em relação à sua área de atuação ${ }^{(14)}$.

Considera-se também que, apesar de louvável a busca dos técnicos de enfermagem pela ascensão profissional, por meio da formação em nível do ensino superior, duas ponderações são relevantes. A primeira é a incongruência da formação em um curso na modalidade de ensino a distância (EaD), pois o Sistema COFEN/COREN posiciona-se contrário à formação do bacharel em enfermagem em tal modalidade de ensino. E a segunda, caracteriza-se pela constatação de que a enfermagem vem demonstrando, ao longo da última década, problemas de empregabilidade plena, situação agravada para a categoria dos enfermeiros. Assim, com o mercado de trabalho insidiosamente mais restrito, milhares desses trabalhadores tendem a submeter-se aos baixos salários e a contratos de trabalho inseguros e precários, com efeitos nocivos à saúde e à qualidade de vida ${ }^{(2-3)}$.

Ao analisar a classe que trata sobre a precarização do trabalho, evidenciou-se que a dupla jornada de trabalho esteve relacionada à influência do modelo neoliberal sobre o trabalho de enfermagem e à questão cultural associada ao multiemprego.

Quer seja atuando no setor público ou no privado, trabalhadores de enfermagem deparam-se 
com salários extremamente baixos, sendo impulsionados a buscar um segundo emprego ${ }^{(2-3,15)}$. Embora trabalhem arduamente e exerçam funções de alto valor social e de grande responsabilidade, por lidarem com vidas humanas, os trabalhadores de enfermagem sofrem com os efeitos da precarização do trabalho.

A precarização do trabalho diz respeito a um conceito multidimensional, que resulta das transformações do trabalho, marcadas pela globalização neoliberal e reestruturação produtiva das últimas décadas do capitalismo global e que podem ser sintetizadas nos processos de flexibilização do trabalho e desregulamentação da legislação trabalhista ${ }^{(16)}$.

Em recente pesquisa, ao avaliar a satisfação profissional de enfermeiros de uma unidade de emergência, quando questionados sobre o retorno financeiro, somente um entre os 15 participantes da pesquisa relatou estar satisfeito com o salário ${ }^{(17)}$. Em comunidade e cenário mundial predominantemente capitalista, a avaliação negativa do empregado quanto ao retorno financeiro pode ser condição importante para diminuição da produção e, ainda, o motivo pelo qual ele se reconhece obrigado ao aumento de vínculos e às extensas jornadas de trabalho, que o tornam susceptível ao sentimento de insatisfação para com a profissão.

Nota-se que os trabalhadores de enfermagem não estão somente expostos à precarização salarial, mas também à precarização do trabalho, pois se deparam com empregos instáveis, resultantes de contratos de trabalho temporário e não dispõem de um piso salarial nacional para a categoria, aspectos que reforçam a desvalorização material/econômica da categoria. A precarização do trabalho define-se com base em um processo histórico-estrutural de degradação do trabalho vivo, o qual ocorre no interior da dinâmica social, reconstituindo as condições de exploração da força de trabalho no modo de produção capitalista ${ }^{(16)}$.

Nesse contexto de precarização, pode-se também identificar a forte presença do ideário neoliberal que vem transformando e impactando negativamente o mundo do trabalho, visto que a lógica de produção capitalista neoliberal engendra uma organização político-econômica pautada em valores exploratórios e de desvalorização da mão de obra, que repercute tanto em instituições públicas quanto privadas ${ }^{(18)}$. Em busca da maximização do lucro, os preceitos neoliberais trazem como consequência a desregulamentação dos direitos sociais e trabalhistas, incentivo ao trabalho precário e ampliação do desemprego estrutural ${ }^{(2,8)}$.

Salienta-se que ainda não é possível mensurar as repercussões das novas leis trabalhistas para o trabalhador de enfermagem, uma vez que a Lei $\mathrm{n}^{\circ} 13.467$, de 13 de julho de 2017, alterou diversos dispositivos da Consolidação das Leis do Trabalho (CLT) ${ }^{(19)}$. No entanto, já existe preocupação crescente em relação ao regime parcial e à terceirização de serviços, por se caracterizarem como prática de gestão, organização e controle da força de trabalho ${ }^{(8)}$.

Nesse contexto de desregulamentação, a não aprovação do piso salarial nacional da enfermagem impacta nas condições gerais de trabalho da categoria. Se, por um lado, a razão utilizada pelo Estado é o impacto financeiro dessa medida, que seria capaz de desestruturar as contas públicas, por outro, é preciso considerar os reflexos positivos desse feito na assistência em saúde, melhorando a qualidade de vida dos trabalhadores e a assistência prestada por eles, uma vez que as condições de trabalho atuais impostas pelo mercado de trabalho estão aquém das condições favoráveis e dignas que a categoria merece e almeja ${ }^{(20)}$.

A Organização Mundial da Saúde (OMS) alerta os líderes políticos sobre a necessária coerência que deve haver no tocante à remuneração dos profissionais de saúde, para que obtenham ganhos financeiros que os atraia para a profissão. Além disso, a remuneração justa e digna possibilita a manutenção e a motivação dos profissionais, para atender às necessidades da população, que são, na verdade, as necessidades do país ${ }^{(21)}$.

No que diz respeito à cultura do multiemprego na enfermagem, a facilidade encontrada pelos trabalhadores em conciliar os vínculos de trabalho e a carência de regulamentação 
de jornada de trabalho específica contribuem para perpetuação da dupla jornada de trabalho. Todavia, a naturalização dessa prática deve servir de advertência às organizações de saúde, aos próprios trabalhadores e, até mesmo, aos pacientes, pois pode mascarar um processo de banalização de sofrimento/adoecimento do trabalhador, articulado pelas estratégias defensivas desses trabalhadores, as quais são engendradas para conseguirem manter-se nesses empregos.

A cultura do multiemprego, ainda que fuja à percepção dos trabalhadores, também se dispõe a atender ao capitalismo, pois, ao possibilitar o envolvimento do trabalhador com mais trabalho e em um processo de autoaceleração, distancia-o de uma prática emancipatória. Trata-se de armadilha psicológica, porque o sujeito confunde a demanda da organização com o próprio desejo, alienando-se ${ }^{(22)}$.

Sem o engajamento dos trabalhadores, não há luta em prol da classe e segue-se, portanto, o desrespeito ao trabalhador e a desregulamentação do trabalho. Por isso e para que consiga escrever uma nova história baseada em reconhecimento e valorização, é tão fundamental que a enfermagem fortaleça-se como categoria, mobilize-se e busque posições de liderança. A militância da classe trabalhadora é fundamental para o combate à precarização do trabalho de enfermagem e o resgate dos direitos que lhe foram subtraídos. Ademais, esta militância não deve ser restrita ao âmbito das entidades de classe, mas deve ter participação ativa dos profissionais, por meio da mobilização coletiva ${ }^{(23)}$.

Ao analisar a classe que trata sobre as aspirações e necessidades dos trabalhadores de enfermagem, verificou-se que a justificativa para adoção e/ou manutenção dos múltiplos empregos e a exposição às duplas jornadas de trabalho não esteve baseada em um paradigma de prosperidade. Trata-se de uma tentativa de resgatar direitos sociais que deveriam ser-lhes assegurados enquanto cidadãos, mas que passaram a ser extremamente atingidos em virtude do ideário neoliberal.

Comumente, os motivos que impulsionam os trabalhadores à dupla jornada de trabalho decorrem da tentativa de garantir a aquisição de direitos mínimos, aos quais todo e qualquer cidadão brasileiro faz jus, a exemplo de moradia, transporte e educação. Em outras palavras, a dupla jornada de trabalho configura-se como a condição minimamente necessária para garantir aos trabalhadores de enfermagem o sustento e a subsistência, em uma sociedade na qual a exploração sem limite da força de trabalho marca as contradições do capitalismo e a lógica destrutiva desse sistema econômico, que não reconhece nenhuma barreira para a precarização do trabalho ${ }^{(8)}$.

Assim, em busca de um futuro melhor e de melhores condições de vida, mesmo cientes das consequências da dupla jornada de trabalho, os trabalhadores de enfermagem permanecem com os múltiplos vínculos por necessidade ${ }^{(24)}$, pois precisam trabalhar intensamente em face da desresponsabilização do Estado e da desvalorização do trabalho humano e do trabalhador ${ }^{(18)}$.

Os trabalhadores de enfermagem com dupla jornada de trabalho buscam a ascensão social não apenas visando produtos de consumo. Eles acreditam que precisam adquirir conhecimento para atender a uma exigência do mercado (qualificação). Assim, em busca de qualificação profissional, os participantes desta pesquisa passam a assumir custos com a faculdade privada, uma vez que, na cidade de Eunápolis e na microrregião, não há universidade pública que oferte o curso de graduação em Enfermagem. Assim, movidos pela expectativa de ascensão social, precisam trabalhar mais para arcar com as despesas educacionais, pois, somente com um emprego, não teriam condições financeiras para concretizar tal intento. Todavia, há de se considerar que não existe busca pelo conhecimento desvinculada de interesses práticos, isto é, espera-se o retorno desse investimento, por meio de retribuição material (econômica) e simbólica (reconhecimento) $^{(14)}$.

Ao considerar a importância e o valor da enfermagem para os serviços de saúde e para a sociedade, é mister que as demandas da categoria sejam reconhecidas e consideradas. Entretanto, não basta reconhecer que a Enfermagem é indispensável para o funcionamento do setor saúde e que profissionais desse campo são capazes 
de solucionar os problemas globais de saúde; é preciso a implementação de políticas e projetos que protejam e valorizem esses trabalhadores e que os líderes políticos tenham clareza de que investir na Enfermagem resulta em retorno positivo para a sociedade. Inclusive, compreendam este investimento como pré-requisito para a prosperidade econômica ${ }^{(25)}$.

Este artigo limitou-se a discutir os motivos que sustentam a prática da dupla jornada de trabalho entre os trabalhadores de enfermagem, com base na percepção dos próprios trabalhadores. É preciso ponderar que, por ter sido utilizado método não probabilístico, não se pôde fazer inferências sobre a população, o que restringe as conclusões. Neste sentido, os dados não poderão ser generalizados, sugerindo-se, então, o desenvolvimento de outras investigações acerca da temática em cenários diferenciados, a fim de confirmar ou confrontar os resultados ora apresentados. Além do exposto, também se indica a realização de estudos com trabalhadores de enfermagem que atuam no setor de ensino, já que estes não fizeram parte desta pesquisa.

Entende-se o reconhecimento da realidade e do contexto de trabalho vivenciado por trabalhadores de enfermagem com dupla jornada de trabalho uma contribuição do presente estudo. Os resultados deste estudo contribuem para a construção do conhecimento relacionado ao trabalho de enfermagem, sugerindo alternativas que promovam a valorização e o reconhecimento desses trabalhadores.

\section{Considerações finais}

O estudo permitiu compreender os motivos que sustentam a prática da dupla jornada de trabalho na enfermagem. As razões incluem a precarização do trabalho da enfermagem, que engloba mais do que a precarização salarial; envolve também as perdas de direitos sociais e trabalhistas, as quais vêm ocorrendo na sociedade atual, em virtude da economia capitalista e da influência do modelo neoliberal sobre o processo de trabalho em enfermagem.

Soma-se ao exposto o fato de que a dupla jornada de trabalho na enfermagem retrata um processo implícito de autoaceleração demandado pelo capitalismo, produzindo ciclo vicioso que é mascarado por uma questão cultural relacionada à facilidade de conciliar múltiplos empregos.

A desregulamentação da jornada de trabalho da enfermagem representa um desafio. Cabe aos trabalhadores de enfermagem, sindicatos e entidades de classe produzirem reflexões e debates no coletivo profissional, a fim de buscarem alternativas para incentivar os trabalhadores ao fortalecimento político, à mobilização e à resistência contra o ideário neoliberal. Há de se propor atos regulatórios junto ao Congresso Nacional, no intuito de ajudar na construção de um arcabouço jurídico capaz de resgatar o respeito, a dignidade, a valorização, a autonomia, a saúde e, especialmente, os direitos desses trabalhadores que desempenham importante função social.

\section{Colaborações:}

1 - concepção, projeto, análise e interpretação dos dados: Samira Silva Santos Soares, Márcia Tereza Luz Lisboa, Ana Beatriz Azevedo Queiroz e Norma Valéria Dantas de Oliveira Souza;

2 - redação do artigo e revisão crítica relevante do conteúdo intelectual: Samira Silva Santos Soares, Márcia Tereza Luz Lisboa, Ana Beatriz Azevedo Queiroz, Karla Gualberto Silva, Jandra Cibele Rodrigues de Abrantes Pereira Leite e Norma Valéria Dantas de Oliveira Souza; 3 - aprovação final da versão a ser publicada: Samira Silva Santos Soares, Márcia Tereza Luz Lisboa, Ana Beatriz Azevedo Queiroz, Karla Gualberto Silva, Jandra Cibele Rodrigues de Abrantes Pereira Leite e Norma Valéria Dantas de Oliveira Souza.

\section{Referências}

1. Machado MH, coordenadora. Pesquisa perfil da enfermagem no Brasil: relatório final. Rio de Janeiro: NERHUS - DAPS - ENSP/Fiocruz; 2015.

2. Souza NVDO, Gonçalves FGA, Pires AS, David HMSL. Neoliberalist influences on nursing hospital work process and organization. Rev Bras 
Enferm. 2017;70(5):912-9. DOI: http://dx.doi. org/10.1590/0034-7167-2016-0092

3. Aspiazu E. Las condiciones laborales de las y los enfermeros en Argentina: entre la profesionalización y la precariedad del cuidado en la salud. Trabajo Soc [Internet]. 2017 [cited 2020 Oct 7];(28):11-35. Available from: http:// www.scielo.org.ar/scielo.php?script=sci arttext\&pid=S1514-68712017000100002\&lng=es\&t $\operatorname{lng}=\mathrm{es}$

4. Rebelo AMS. Descanso noturno: influências da ergonomia na adaptação do trabalho de enfermagem [Internet]. [dissertação]. Rio de Janeiro (RJ): Universidade do Estado do Rio de Janeiro; 2017 [cited 2020 Jul 17]. Available from: http://www.bdtd.uerj.br/tde_busca/arquivo. php?codArquivo $=12897$

5. Quirino GS, Leite MF, Belém JM, Nunes JFC, Albuquerque GA. Double work shift: implications on nurses' health. Rev Enferm UFPE online. 2016 [cited 2019 Jul 18];10(9):3401-10. Available from: https://periodicos.ufpe.br/revistas/ revistaenfermagem/article/view/11422/13212

6. Santos NPC, Gama VS, Lefundes EB, Santos LM, Passos SSS, Silva SSB. Percepção de enfermeiras com dupla jornada de trablho sobre a segurança do paciente. Rev baiana Saúde Pública. 2018;42(0):a2878. DOI: https://doi.org/ $10.22278 / 2318-2660$

7. Lima MB, Silva LMS, Almeida FCM, Torres RAM, Dourado HHM. Agentes estressores em trabalhadores de enfermagem com dupla ou mais jornada de trabalho. R pesq: cuid fundam online. 2013;5(1):3259-66. DOI: 10.9789/2175$5361.2013 v 5 n 1 p 3259$

8. Antunes R, Praun L. A sociedade dos adoecimentos no trabalho. Serv Soc Soc. 2015;(123):407-27. DOI: https://doi.org/10.1590/0101-6628.030

9. Tong A, Sainsbury P, Craig J. Consolidated criteria for reporting qualitative research (COREQ): a 32-item checklist for interviews and focus groups. Int J Qual Health Care. 2007 [cited 2019 Nov 2];19(6):349-57. Available from: https:// academic.oup.com/intqhc/article/19/6/ 349/1791966

10. Brasil. Ministério da Saúde. Cadastro Nacional de Estabelecimentos de Saúde. Extração de dados de profissional [Internet]. Brasília (DF); 2018 [cited 2018 Sep 22]. Available from: http://cnes.saude. gov.br/pages/profissionais/extracao.jsp
11. Instituto Brasileiro de Geografia e Estatística. Cidades e Estados: Eunápolis [Internet]. Brasília (DF); 2018 [cited 2018 Aug 16]. Available from: https://www.ibge.gov.br/cidades-e-estados/ba/ eunapolis.html

12. Camargo BV, Justo AM. Tutorial para uso do software Iramuteq. Santa Catarina: Laboratório de Psicologia Social da Comunicação e Cognição/ UFSC/Brasil; 2016 [cited 2018 Sep 20]. Available from: http://www.iramuteq.org/documentation/ fichiers/Tutorial\%20IRaMuTeQ\%20em\%20 portugues_17.03.2016.pdf

13. Maissiat GDS, Lautert L, Dal Pai D, Tavares JP. Work context, job satisfaction and suffering in primary health care. Rev Gaúcha Enferm. 2015;36(2):42-9. DOI: http://dx.doi. org/10.1590/1983- 1447.2015.02.51128

14. Wermelinger M, Lima JCF, Vieira M. A formação do auxiliar e do técnico em enfermagem: a 'era SUS'. Divulg Saúde Debate. 2016 [cited 2019 Jul 25];(56):19-35. Available from: http:// cebes.org.br/site/wp-content/uploads/2016/12/ Divulga\%C3\%A7\%C3\%A3O_56_Cofen.pdf

15. Machado MH, Oliveira E, Lemos W, Lacerda WF, Aguiar Filho W, Wermelinger $M$, et al. Mercado de trabalho da enfermagem: aspectos gerais. Enferm Foco [Internet]. 2016 [cited 2019 Jul 29];6(1/4):43-78. Available from: http://revista. cofen.gov.br/index.php/enfermagem/article/ view/691/301

16. Alves G. Precarização do trabalho e saúde do trabalhador. In: Mendes R, organizador. Dicionário de saúde e segurança do trabalhador: conceitos, definições, história, cultura. Novo Hamburgo (RS): Proteção; 2018.

17. Cordeiro MG, Torres AMA, Rocha FAA, Costa FBC, Branco JGO. Satisfação profissional de enfermeiros em uma unidade de emergência. Rev Nursing [Internet]. 2019 [cited 2019 Jul 29];22(249):2604-9. Available from: http://www.revistanursing.com.br/ revistas/249/pg17.pdf

18. Oliveira EA. A funcionalidade da política social e os limites da emancipação humana na ordem do capital. SER Social [Internet]. 2015 [cited 2019 Jul 25];17(37):348-67. Available from: http:// periodicos.unb.br/index.php/SER_Social/article/ view/13436/11764

19. Brasil. Ministério do Trabalho. Lei $n^{-} 13.467$, de 13 de julho de 2017. Altera a Consolidação das Leis do Trabalho (CLT), aprovada pelo Decreto-Lei 
$\mathrm{n}^{\mathrm{o}}$ 5.452, de $1^{\circ}$ de maio de 1943 , e as Leis $\mathrm{n} \cong 6.019$, de 3 de janeiro de 1974, 8.036, de 11 de maio de 1990, e 8.212, de 24 de julho de 1991, a fim de adequar a legislação às novas relações de trabalho [Internet]. Brasília (DF); 2017 [cited 2019 Jul 29]. Available from: https://www.planalto.gov. br/ccivil_03/_ato2015-2018/2017/lei/113467.htm

20. Caetano AS, Prado JTC. Mercado de trabalho: condições gerais do trabalho da enfermagem. Rev Divulg Saúde Debate [Internet]. 2016 [cited 2020 jul 12];(56):98-105. Available from: http:// cebes.org.br/site/wp-content/uploads/2016/12/ Divulga\%C3\%A7\%C3\%A3O_56_Cofen.pdf

21. World Health Organization. State of the World's nursing 2020 [Internet]. Genebra; 2020 [cited 2020 Oct 7]. Available from: https://www.who.int/ publications/i/item/9789240003279

22. Dejours C. A banalização da injustiça social. 7a ed. Rio de Janeiro (RJ): FGV; 2006.
23. Salvage J. Editorial. Uma nova história da enfermagem. Rev Enf Ref [Internet]. 2018 [cited 2020 Oct 7];serIV(17):3-12. Available from: http://www.scielo.mec.pt/scielo.php?script=sci_ arttext\&pid=S0874-02832018000200001\&lng=pt

24. Cechin P, Freitas HMB, Ilha S, Martins ESP, Souza MHT. Alterações vivenciadas por profissionais de enfermagem que apresentam dupla jornada de trabalho. Rev enferm UFPE on line. 2014;8(11):3855-61. DOI: 10.5205/ reuol.6679-58323-1-ED.0811201406

25. Catton H. International council of nurses workforce forums. Philadelphia (PA); 2018 [cited 2020 Oct 7]. Available from: https://www.icn. ch/sites/default/files/inline-files/2018_Pay\%20 data\%20analysis.pdf

Recebido: 10 de outubro de 2020

Aprovado: 14 de outubro de 2020

Publicado: 24 de novembro de 2020

A Revista Baiana de Enfermagem utiliza a Licença Creative Commons - Atribuição-NãoComercial 4.0 Internacional.

https://creativecommons.org/licenses/by-nc/4.0/

Este artigo é de acesso aberto distribuído sob os termos da Licença Creative Commons (CC BY-NC).

Esta licença permite que outros remixem, adaptem e criem a partir do seu trabalho para fins não comerciais. Embora os novos trabalhos tenham de lhe atribuir o devido crédito e não possam ser usados para fins comerciais, os usuários não têm de licenciar esses trabalhos derivados sob os mesmos termos. 